\title{
Ancestrais enquanto pessoas mais velhas do gru- po de parentesco na África ${ }^{1}$
}

\author{
IGOR KOPYTOFF $^{2}$
}

Os chamados 'culto aos ancestrais' e 'adoração aos ancestrais' saltam aos olhos na imagem antropológica da África Sub-saariana e poucos discordariam de Fortes que "visto comparativamente, a veneração africana aos ancestrais tem uma notável base estrutural comum" (Fortes, 1965 , p. 122$)^{3}$. O padrão geral pode ser resumido rapidamente. Ancestrais são revestidos de poderes e autoridade místicos. Eles mantêm um papel funcional no mundo dos vivos, especificamente na vida dos seus parentes vivos; de fato, os grupos de parentesco africanos são geralmente descritos como comunidades tanto de vivos quanto de mortos. A relação dos ancestrais com os parentes vivos tem sido descrita como ambivalente, como sendo tanto punitiva como benevolente e algumas vezes até mesmo caprichosa. Em geral, a benevolência ancestral é assegurada através do apaziguamento e do sacrifício; acredita-se que a negligência acarreta em punição. Ancestrais estão intimamente envolvidos com o bem estar do seu grupo de parentesco, mas eles não estão ligados da mesma forma a todos os membros daquele grupo. A ligação é estruturada através das pessoas mais velhas do grupo de parentesco, e a autoridade das pessoas mais velhas [do grupo de parentesco] está relacionada com sua forte ligação com os ancestrais. Em algum sentido as pessoas mais velhas [do grupo de parentesco] são as representantes dos ancestrais e as mediadoras entre eles e o grupo de parentesco.

Recentemente, Fortes estendeu nosso entendimento teórico acerca da adoração africana aos ancestrais ao esclarecer melhor alguns dos seus aspectos estruturais (Ib., Idem). Ampliando a distinção feita por Gluckman (1937) entre cultos aos ancestrais e cultos aos mortos, Fortes revela a importância da "matriz estrutural da adoração aos ancestrais [na África]", constatando inter alia a relativa falta de elaboração, e até mesmo de interesse, que os africanos têm acerca da cosmografia do mundo do além, onde os ancestrais residem. A ênfase africana está claramente na maneira por meio da qual os mortos afetam os vivos e não em como os mortos vivem. Diferentes ancestrais são reconhecidos como relevantes em diferentes contextos estruturais (por exemplo, em grupos de níveis genealógicos diferentes); nem todos os mortos são adorados como ancestrais, mas somente aqueles com posiçóes estruturais particulares; e o comportamento do ancestral não reflete sua personalidade, mas sim um status legal particular no domínio político-jural ${ }^{4}$.

Nesse paper eu descreverei algumas atividades e alguns relacionamentos entre os Suku do sudoeste do Congo (Kinshasa). Ficará evidente que a descrição realizada concorda com o padrão generalizado dos cultos africanos aos ancestrais e é congruente com a análise de Fortes $^{5}$. Contudo, eu mostrarei que existem dificuldades na caracterização do complexo Suku como um 'culto aos ancestrais' e trarei dados adicionais sobre a estrutura de linhagem Suku. Argumentarei posteriormente que a análise de Fortes, embora aponte para a direçâo correta, não vai longe o bastante porque ela não dá o passo final de derrubar as conota- 
234 | IgOr KopytofF

çóes etnocêntricas do termo 'ancestrais' - conotaçóes que têm uma implicação na teoria. Eu também tentarei mostrar que, ao ver o que foi chamado de cultos africanos aos ancestrais como parte do complexo da senioridade, nós podemos lidar de maneira mais simples com muitas das generalizaçóes de Fortes e, assim, alguns dos problemas que ele levanta tornam-se redundantes.

O grupo jural e social fundamental entre os Suku é a linhagem corporada matrilinear, geralmente consistindo algo entre trinta e cinco, quarenta pessoas. Casais casados vivem virilocalmente, e homens vivem patrilocalmente, pelo menos até a morte do seu pai e muitas vezes além desse período. $\mathrm{O}$ pertencimento a uma matrilinhagem é disperso em diversas aldeias, as quais estão, porém, dentro de uma área que não é larga o bastante para impedir que haja fácil comunicação, consultas e realização de ações conjuntas em questôes importantes. A matrilinhagem é uma unidade corporada nos âmbitos econômico, político, jural e religioso. Cada matrilinhagem está concentrada em uma aldeia particular, a qual carrega seu nome e hospeda suas sedes administrativa e ritual, onde se encontra a cabeça formal da linhagem (o membro masculino mais velho) e, geralmente, muitos outros membros mais velhos (Kopytoff, 1964, 1965).

Os membros mortos da linhagem, enquanto uma coletividade, são convocados em momentos de crise (tais como uma doença grave ou uma série de infortúnios) e, mais regularmente, em certas ocasióes, como os casamentos de mulheres da linhagem ou como a cerimônia de iniciação para as crianças, e, anualmente, antes das grandes caças comunitárias da estação seca. O padrão geral é o que segue: aquele que é a cabeça da linhagem vai, durante a noite, junto com dois ou três homens mais velhos de sua geração, para a sepultura - qualquer sepultura - de um membro falecido da linhagem que fosse mais velho do que qualquer um deles. Os Suku não tem um lugar especial para enterrar e os túmulos são escavados a esmo no mato, fora do centro da linhagem ou perto de cruzamentos; as sepulturas não são preservadas e elas eventualmente voltam a ser mato, de modo que o lugar de uma sepultura particular é geralmente esquecido com o passar do tempo. O lugar das sepulturas recentes é, obviamente, lembrado; a cabeça da linhagem e os homens mais velhos geralmente vão até à sepultura do último homem falecido que era mais velho que eles. $\mathrm{O}$ cruzamento entre caminhos é outro lugar apropriado para dirigir-se aos mortos.

Na sepultura ou nos cruzamentos, os homens velhos 'alimentam' os mortos com certas comidas consideradas suas favoritas: tipos particulares de cogumelos da floresta e de raízes selvagens, vinho de palma, e algumas vezes mesmo mandioca - a base da alimentação Suku. Um pequeno buraco é escavado no chão e a comida é colocada nele. A comunicação com os mortos assume a forma de uma conversa monológica, padronizada, mas não estereotipada, e desprovida de fórmulas repetitivas. Fala-se da maneira em que se falaria com pessoas vivas:

Você (tal e tal), sua pessoa mais nova [do grupo de parentesco] está mal ${ }^{6}$. Nós não sabemos por que ela está assim, nós não sabemos quem é responsável por isso. Caso você seja o responsável, pedimos seu perdão se você estiver bravo. Se fizemos algo errado, desculpe-nos. Não deixe que essa pessoa morra. Outras linhagens estão prosperando e nossas pessoas estão morrendo. Por que você está fazendo isso? Por que você não toma conta de nós adequadamente? 
ANCESTRAIS ENQUANTO PESSOAS MAIS VELHAS DO GRUPO DE PARENTESCO NA África $\mid 235$

As palavras tipicamente combinam queixas, broncas, algumas vezes raiva, ao mesmo tempo em que apelam para o perdão.

Nas cerimônias de iniciação das crianças e nos casamentos, os membros mortos da linhagem são informados do evento que está ocorrendo; pedidos são feitos para que eles concedam sua aprovação e seus esforços para assegurar o sucesso do recém-nascido ou o sucesso do casamento e das crianças que irão nascer dele. Antes das grandes caças comunais na estação da seca, pede-se que os membros mortos concedam boa sorte à empreitada. É dito a eles que as pessoas estão com fome de carne, eles são repreendidos por não concederem carne suficiente, e eles são constrangidos pelo fato de que suas próprias pessoas irão comer pior do que as pessoas de outras linhagens.

Finalmente, em todas as ocasióes que envolvem a linhagem enquanto uma unidade, os membros mortos da linhagem são sempre chamados publicamente pelas pessoas mais velhas [do grupo de parentesco] que estão vivas.

Essas atividades Suku claramente se encaixam no padrão geral dos 'cultos africanos aos ancestrais'. Os ancestrais são vistos como mantendo sua função nas atividades do seu grupo de parentesco e exclusivamente do seu grupo de parentesco. Eles são propiciados com 'sacrifícios'. Eles são vistos como concedendo tanto favores quanto infortúnios; eles são geralmente acusados de serem caprichosos e de falhar em cumprir suas responsabilidades, mas, ao mesmo tempo, suas ações são relacionadas a possíveis lapsos por parte dos vivos e são vistas como legitimamente punitivas. Os aspectos do 'culto' enfatizam a natureza dos relacionamentos sociais, ignorando detalhes da vida dos ancestrais no outro mundo, os quais são, de fato, de pouco interesse para os Suku. É principalmente o contexto jural que domina o relacionamento com os ancestrais e não as características pessoais que eles podem ter tido quando eles eram vivos.

Existe, entretanto, um problema imediato que surge ao chamarmos o que foi descrito acima de 'culto aos ancestrais': os Suku não têm um termo que pode ser traduzido como 'ancestrais'. Esses membros mortos da linhagem são chamados por eles de bambuta. Literalmente, bambuta significa os 'grandes', os 'velhos', aqueles que adquiriram maturidade, aqueles que são mais velhos do que si mesmo; coletivamente, o termo se refere às pessoas mais velhas [do grupo de parentesco] que estão no comando da linhagem. Um mbuta (singular) é literalmente qualquer um que seja mais velho do que ego. O significado é comparativo. Senioridade não é ser velho em estado absoluto; ser um mbuta é sempre relativo a alguém que é mais novo. Dentro da linhagem, um mbuta é qualquer adulto mais velho, irmãos mais velhos, bem como qualquer um das geraçóes acima. Meus bambuta coletivamente são todos os membros da linhagem que são mais velhos que eu, independentemente deles estarem vivos ou mortos. Em contextos jurais, onde a autoridade é investida esmagadoramente aos homens, o termo é de fato restrito a todos meus seniores masculinos. A linhagem é dividida em dois grupos assim nomeados: aqueles acima de mim que são meus bambuta, e aqueles abaixo de mim - meus baleke - para os quais eu sou uma pessoa mais velha. Por outro lado, não é feita nenhuma distinção semântica dentro da linhagem entre aqueles que estão vivos e aqueles que estão mortos.

Uma pessoa mais velha [do grupo de parentesco] - qualquer pessoa mais velha [do grupo de parentesco] - representa para uma pessoa mais nova [do grupo de parentesco] toda a autoridade mística e legal da linhagem. A senioridade por si só confere a uma pessoa poderes místicos sobre a pessoa mais nova [do grupo de 
parentesco]. Em nome da linhagem, ele pode amaldiçoar sua pessoa mais nova [do grupo de parentesco], removendo assim a proteção mística que ele recebe da linhagem. A maldição pode ser formal e pública, mas ela pode ser também secreta e até mesmo inconsciente. Para usar uma metáfora contemporânea, um Suku está sob o 'guarda-chuva' de poder da sua linhagem; a remoção dessa proteção o expóe ao mundo exterior, e o mundo é um lugar perigoso quando não se está ligado ao grupo de parentesco. Como dizem os Suku, uma maldição "abre o caminho para o infortúnio"; embora ela não cause ativamente infortúnios. Uma maldição da pessoa mais velha [do grupo de parentesco] é sempre feita implicitamente em nome da linhagem e só pode ser removida por uma pessoa mais velha [do grupo de parentesco] que seja ainda mais velha do que o parente que amaldiçoou - isso é, por um parente em relação ao qual aquele que amaldiçoou é uma pessoa mais nova [do grupo de parentes$\mathrm{co}]^{7}$

A autoridade da linhagem e a representação da linhagem para o mundo exterior são ambas organizadas sobre um contínuo de idade, isto é, de senioridade relativa. Dentro desse contínuo formal, baseado puramente na idade relativa, existe também o princípio da solidariedade geracional. Os membros da linhagem da mesma geração são próximos uns aos outros e tendem em direção a uma maior equidade, ainda que ela nunca seja alcançada. Assim, a desigualdade de poder e de autoridade é mais proeminente entre gerações. Sob circunstâncias normais, é uma atitude extremamente presunçosa a geração júnior questionar as decisóes da geração sênior e as maneiras pelas quais chegou-se a elas. É a geração acima de mim que representa, para mim, toda a autoridade da linhagem; solidariedade geracional bem como distância inter-geracional significam que, a menos que eu seja informado do contrário, eu devo supor que a decisão de um sênior representa a decisão de todos os seniores. Essa estrutura geracional também expressa um contínuo de autoridade. Se eu sou alguém de meia idade, a decisão das pessoas mais velhas [do grupo de parentesco] da geração acima carrega para mim a autoridade de todas as geraçóes seniores acima de mim. Para um júnior na geração abaixo da minha, minha decisão carrega, similarmente, a autoridade da minha geração junto com a autoridade de todas as gerações que são seniores em relação à minha. Portanto, para o júnior, a autoridade da linhagem está mais diretamente corporificada na geração imediatamente acima dele e é uma atitude presunçosa dele, por assim dizer, passar por acima das cabeças daqueles, isso é, pular sua geração sênior, dirigindo-se diretamente às geraçóes ainda mais seniores. Reciprocamente, a autoridade da senioridade é exercida mais diretamente sobre aqueles da geração imediatamente abaixo; por sua vez, as pessoas dessa geração exercem legitimamente autoridade sobre a geração abaixo deles. De certo modo, é inapropriado exercer autoridade sobre a segunda geração que está abaixo da própria, passando acima das cabeças da geração que deveria intervir. Isso resulta em silenciar a expressão externa da autoridade entre as geraçôes alternadas da linhagem, um padrão congruente com a etiqueta frouxa que caracteriza o comportamento entre geraçóes alternadas.

Em qualquer contexto, a linhagem é representada total e legalmente pela pessoa presente que é o membro adulto mais velho da linhagem. Deixe-me dar alguns exemplos. Assim como em muitos outros povos da África Central, a cabeça da linhagem carrega o nome de sua linhagem. Assim, aquele que é a cabeça de linhagem Kusu é nomeado como Kusu. Mas essa regra geral expressa uma estrutura mais complexa. A identificação do nome da 
ANCESTRAIS ENQUANTO PESSOAS MAIS VELHAS DO GRUPO DE PARENTESCO NA África $\mid 237$

linhagem com a pessoa se estende a todos os membros da linhagem. É a linhagem como um todo, qua grupo corporado, que carrega o título. Cunnison (1951), escrevendo sobre os povos Luapula, analisou esse uso particular no qual uma pessoa discutindo sua linhagem e a história desta no passado, irá se referir à linhagem através do pronome 'eu'. Existe um uso similar entre os Suku. O membro mais velho da linhagem que está presente em qualquer situação pode se referir a si mesmo pelo nome da sua linhagem, e os outros se dirigem a ele dessa forma. Por exemplo, desde que nenhum outro membro mais velho da linhagem esteja presente, as pessoas se dirigem a uma criança que pertence à linhagem real como Mini Kongo - título do rei Suku. No momento em que um membro mais velho entra em cena, o título é deslocado para ele. Um homem jovem da linhagem Kusu irá referir a si mesmo como Kusu e, logo em seguida, após a chegada de um homem mais velho, ele irá se referir a esse último como Kusu e não aplicará mais o título a si mesmo. Em última análise, é claro que, se todos os membros da linhagem estão presentes, o título Kusu recai sobre o membro mais velho, que é também o cabeça formal da linhagem.

Ao representar a linhagem, o contínuo da senioridade tem uma significância jural nas relaçôes internas à linhagem. Deixe-me oferecer um exemplo extremo para ilustrar esse aspecto. Um jovem homem ficou bravo com suas pessoas mais velhas [do grupo de parentesco] e, sem consultar ninguém, vendeu para outra linhagem uma área de caça pertencente à própria linhagem. Essa transação foi completamente legal, uma vez que ele era um porta-voz legítimo da sua linhagem no contexto em que a transação ocorreu. Sua própria linhagem foi, é claro, afetada pela ação; em tempos passados ele poderia ser vendido ou mesmo morto. Mas o ponto significativo aqui é que a legalidade da transação não foi questionada.

Em suma, para aqueles de fora, a linhagem é representada pelos membros mais velhos que estão presentes. Dentro da linhagem, ela é representada, para qualquer membro, por qualquer outro membro mais velho presente, e, coletivamente, por todos os membros mais velhos vivos e mortos. O princípio de senioridade que opera dentro da linhagem corresponde, nas suas relações externas, a sua 'chefia' (Kimfumu). A 'chefia' da linhagem também é uma questão relativa, não absoluta; para o mundo exterior aquele que carrega a chefia da linhagem é o membro mais velho presente. Assim, os Suku dizem que 'todos são chefes' assim como todos são pessoas mais velhas [do grupo de parentesco].

Vamos considerar agora alguns aspectos adicionais do ritual que precede a caça coletiva da estação da seca. Antes da estação da caça começar, cada Suku assegura sorte na caça obtendo a garantia de que a linhagem deseja-lhe o bem, ou seja, deseja que ele continue sob proteção da linhagem. Essa garantia pode, a princípio, ser obtida verbalmente de qualquer pessoa mais velha [do grupo de parentesco]; mais especificamente, ela é obtida de qualquer um da geração acima. Homens jovens recorrem aos de meia idade e os homens de meia idade aos velhos. Existe um padrão para pedir por boa sorte: suplica-se, queixa-se, reprova-se, pede-se perdão. Da sua parte, o homem mais velho exprime sua benevolência dando à pessoa mais nova [do grupo de parentesco] alguma pemba (pó branco); ele também usa a ocasião para lembrar ao jovem homem suas obrigaçóes com os velhos, para repreendê-lo levemente por suas contravençôes passadas e para pedir-lhe perdão pelos infortúnios passados. A forma de dirigir-se à pessoa mais velha [do grupo de parentesco] que está viva 
238 | IgOR KopytofF

é a mesma usada para dirigir-se aos mortos. Os Suku consideram essas duas maneiras de agir como sendo idênticas e não meramente análogas; além disso, concebem as diferenças entre elas como casuais e contextuais. Todos se dirigem às suas pessoas mais velhas [do grupo de parentesco]. Se eu sou jovem eu me dirijo às minhas pessoas mais velhas [do grupo de parentesco] que estão vivas. As pessoas velhas se dirigem às suas pessoas mais velhas [do grupo de parentesco]; contudo, uma vez que essas últimas estão mortas, elas devem ser encontradas no túmulo ou nas encruzilhadas à noite. Tendo em vista o contínuo da senioridade, é compreensível que se utilize qualquer túmulo, desde que o morto seja mais velho do que o suplicante. Nesse contexto, também é compreensível que se negligencie os túmulos mais velhos. À luz da estrutura da senioridade, esta negligência não representa um culto 'fraco' aos ancestrais nem indica superficialidade da estrutura da linhagem.

Se existe um 'culto' aqui, é o culto do bambuta, das pessoas mais velhas [do grupo de parentesco] que estáo vivas e mortas. Toda pessoa mais nova [do grupo de parentesco] deve bizutu ('honra', 'respeito') aos seus seniores, sejam eles 'pessoas mais velhas [do grupo de parentesco]' ou 'ancestrais' na terminologia ocidental. Um conjunto único de princípios regula o relacionamento entre sênior e júnior; uma pessoa lida com uma única categoria de bambuta e a linha que divide os vivos dos mortos náo afeta a estrutura do relacionamento. Essa linha só é relevante no método adotado para abordar a pessoa mais velha [do grupo de parentesco]. Os mortos devem necessariamente ser abordados diferentemente dos vivos; a interação com eles necessariamente assume uma aparência assimétrica e as conversas com eles necessariamente tornam-se monólogos. Além disso, a interação com eles é necessariamente menos frequente e quando ela ocorre é formal - mas não menos formal do que a interação, em ocasióes cerimoniais, com as pessoas mais velhas [do grupo de parentesco] que estão vivas. Oferecer vinho de palma é normal em todas as ocasióes quando um júnior aborda um sênior; mas pessoas mais velhas [do grupo de parentesco] que estão mortas, na sua condição de mortos, também têm suas comidas preferidas - os cogumelos especiais da floresta e as raízes. Assim, são os métodos especiais de abordagem que inevitavelmente caracterizam os procedimentos com os mortos como opostos àqueles com os vivos, conferindo àqueles procedimentos o aspecto especial que faz com que nós, enquanto antropólogos e outsiders, chamemos esses métodos de 'culto'. Os mortos qua mortos também sabem mais e vêem coisas que as pessoas mais velhas [do grupo de parentesco] que estão vivas não sabem e não vêem; eles são, portanto, mais poderosos e às vezes podem ser mais prestativos. Além disso, ainda que as razóes das açóes de qualquer pessoa mais velha [do grupo de parentesco] sejam frequentemente obscuras para as pessoas mais novas [do grupo de parentesco], as ações das pessoas mais velhas [do grupo de parentesco] são sempre particularmente obscuras uma vez que nunca é possível obter explicaçóes por parte dessas pessoas. Em suma, existe uma diferença na maneira pela qual os mortos são abordados, em comparação com os vivos. Mas a diferença está relacionada com o diferente estado físico que as pessoas adquirem quando morrem, mesmo quando elas permanecem na mesma posição estrutural vis$-\grave{a}$-vis suas pessoas mais novas [do grupo de parentesco].

O padrão Suku descrito acima é congruente com a maioria das descriçóes etnográficas dos 'cultos africanos aos ancestrais' e do papel 
ANCESTRAis ENQUANTO PESSOAS MAIS VELHAS Do GRUPO DE PARENTESCO Na África 239

das pessoas mais velhas [do grupo de parentesco]. O caso Suku poderia parecer distinto no que tange ao padrão semântico e linguístico que o acompanha. Tal padrão engloba sob o único termo mbuta o contínuo da senioridade enquanto negligencia a linha entre os vivos e os mortos. Mas os Suku estáo longe de serem os únicos a fazerem isso. Evidências linguísticas comparativas sugerem que, na África (particularmente na África Bantu), está disseminada uma fusão ou uma associação semântica muito próxima entre 'ancestrais' e 'pessoas mais velhas [do grupo de parentesco] que estão vivas' ${ }^{8}$.

A tabela que segue mostra a distribuição dos radicais usados em várias línguas Bantu para formar termos que foram traduzidos como 'ancestrais' e como 'pessoas mais velhas [do grupo de parentesco]'. Pode-se observar que também em Ovambo, Lele, Songye, Nkundo, Bobangi, Ila, Lamba, Yao, Bondei, Bantu-Tiriki e Zulu encontra-se uma situação similar àquela dos Suku, com seu termo único 'ancestral/pessoa mais velha [do grupo de parentesco]'. Entre os Kongo, Ntomba, Yao, Ankole, e Karanga encontram-se termos separados que, ainda assim, são muito semelhantes e derivam do mesmo radical. Será possível observar também que, quando os termos para 'ancestrais' e 'pessoas mais velhas [do grupo de parentesco]' são reportados como sendo diferentes, ou quando existem termos alternativos, ainda assim, os termos separados derivam dos mesmos radicais que apareceram nos casos precedentes. Finalmente, existe um padrão ocasional no qual um único termo representa 'avô/ancestral'.

Três radicais bantu comuns destacam-se na tabela: -kulu,-kale e -koko.

O núcleo semântico de -kulu (-kuru, -kolo, -koro, -guru) é 'crescer, tornar-se grande' e seu campo semântico usual em língua Bantu inclui 'crescer, amadurecer, tornar-se adulto, tornarse velho, ser importante' (com seus adjetivos respectivos e suas formas substantivas). Em muitas linguas existe uma derivação semântica em direção a 'mais velho' (comparativo) e em direção a 'pessoa mais velha' (substantivo). Em algumas línguas existe alguma derivação ulterior em direção a 'os mais velhos', usado no sentido do termo inglês 9 'ancestors'. (A direçâo da derivação semântica vai desde a 'pessoa mais velha [do grupo de parentesco]' em si, até a combinação 'pessoa mais velha [do grupo de parentesco]/ancestral'.) Assim, uma tradução apropriada do núcleo semântico de -kulu poderia ser o francês 'grand' (com com seu verbo assossiado 'grandir), e a expressão 'pessoa mais velha [do grupo de parentesco]/ancestrais' formada com esse radical deveria ser traduzido como 'les grands' (um termo que, de fato, africanos falantes de francês usam algumas vezes com adequação semântica surpreendente: 'les grands, afinal de contas, podem estar tanto vivos como mortos) $)^{10}$.

O termo -kulu, diferente de -koko, aparenta ser um termo semanticamente primário e o padrão dessa derivação semântica está na direção oposta: significa desde 'ancestral' em si, até 'ancestral/avô' ou 'ancestral/avô/pessoa mais velha [do grupo de parentesco]'. Nesse caso, o núcleo semântico é talvez melhor traduzido como 'antepassado'.

O terceiro radical usado -kale é um termo Bantu comum para 'há muito tempo', 'antigamente', 'idoso', 'antigo', 'antecedente no tempo' etc. (assim como - kulu, esse termo também está entre as formas Ur-Bantu de Meinhof). Uma forma apropriada de transmitir o significado central é 'antigo' na sua referência primária à escala de tempo, àquilo cuja 'data remonta ao passado', e na sua referência secundária a 'velho' (quando essa palavra indica o estado de um sujeito enquanto indicativo de sua posiçâo 
240 | IgOR KOPYTOFF

\section{Tabela}

O uso dos radicais comuns na formação de termos para 'pessoas mais velhas [do grupo de parentesco]' $e$ 'ancestrais' nas linguas Bantu selecionadas.

Nota: Ancestrais 'anc': Pessoa mais velhas [do grupo de parentesco]:'pmv'; avô ou avós: 'avós'.

Uma barra oblíqua significa que um único termo africano combina os dois ou os três termos em português (ex.'anc/pmv' indica que um termo significa ao mesmo tempo'ancestral'e'pessoa mais velha').

Uma vírgula significa que dois termos são construídos a partir do mesmo radical (ex. Em Karanga, makuru,'pessoa mais velha'e vakuru, 'ancestrais').

\begin{tabular}{|c|c|c|c|c|c|}
\hline & & & Radical usado & & \\
\hline & -kale & -kulu & -koko & -ka(ka) & outro \\
\hline Ovambo & & anc/pmv & & & \\
\hline Kongo & & anc, pmv & & & pmv (-uta) \\
\hline Suku & & & & & anc/pmv (-uta) \\
\hline Lele & & & & & anc/pmv (-ota) \\
\hline Songye & pmv & anc, pmv & & & \\
\hline Nkundo & & & anc/avós/pmv & anc & pmv (-gambi) \\
\hline Ntomba & & & anc, pmv & anc/avós & pmv (-gambi) \\
\hline Ngala & pmv & pmv & anc/avós & & \\
\hline Bobangi & & & anc/avós/pmv & & \\
\hline $\mathrm{Ila}$ & anc/pmv & & & avós & pmv (-alu) \\
\hline Lamba & anc & anc/pmv & & & \\
\hline Yao & anc/pmv & anc, pmv & & & anc/pmv \\
\hline \multicolumn{6}{|l|}{ (-kolo) } \\
\hline Ankole & pmv & pmv, anc/avós & & & \\
\hline Bondei & & pmv & & & anc/pmv \\
\hline \multicolumn{6}{|l|}{ (-dala) } \\
\hline Tiriki & & pmv & & & $\begin{array}{l}\text { anc/avós/pmv } \\
\text { (-guga) }\end{array}$ \\
\hline Karanga & & pmv, anc & & & \\
\hline Zulu & & $\mathrm{pmv} / \mathrm{anc}$ & anc/avós & & Pmv \\
\hline (-guga, -dala) & & & & & \\
\hline
\end{tabular}

numa escala de tempo). A menos que se escolha a incômoda palavra 'antecedente', é o substantivo francês 'les anciens' que parece traduzir melhor esse núcleo de significado com suas implicaçóes (e africanos francófonos usam por vezes esse termo). A derivação semântica de -kale vai, por vezes, apenas na direção de 'pessoa mais velha [do grupo de parentesco]', outras vezes, apenas na direção de 'ancestral', e outras vezes ainda, vai na direção da combinação 'ancestral/ pessoa mais velha [do grupo de parentesco]' ('les anciens' pode referir-se apropriadamente aos vivos ou aos mortos ou a ambos).

Outros radicais menos comuns que estão 
ANCESTRAIS ENQUANTO PESSOAS MAIS VELHAS Do GRUPO DE PARENTESCO NA África $\mid$ 24I

presentes na formação daquilo que nós traduzimos como 'ancestrais' e/ou 'pessoas mais velhas [do grupo de parentesco]' são -dala ('velho' ou 'distante no tempo') e -alu (que pode ou não estar relacionado a -kale); -ka ou -kaka, usados para 'avô' ou 'avô/ancestral' ('antepassado'?); e -utal-ota (como no Suku mbuta) cujo núcleo de significado é 'criar/aguentar'.

Portanto, na África Bantu existem ao menos três maneiras principais por meio das quais são expressas as ideias associadas de 'senioridade' e 'ancestralidade'. Uma, por meio da derivação semântica 'tornar-se grande', na qual 'pessoas mais velhas [do grupo de parentesco]' ou 'ancestrais/pessoas mais velhas [do grupo de parentesco]' assume o mesmo significado que 'les grands'. A segunda, por meio da derivação semântica de 'antigo', na qual 'ancestrais' ou 'pessoas mais velhas [do grupo de parentesco]' ou 'ancestrais/pessoas mais velhas [do grupo de parentesco]' assumem o mesmo significado que 'les ancients'. A terceira, por meio do uso de um termo primário para 'ancestral' que, através de uma derivação semântica, pode englobar 'ancestral/avô' e até mesmo 'ancestral/avô/pessoa mais velha [do grupo de parentesco]'.

A associação semântica entre 'ancestral' e 'pessoa mais velha [do grupo de parentesco]' não se restringe às línguas Bantu. Em Igbo, nnà é utilizado seja para 'parente masculino mais velho', seja para 'ancestral'. Em Mossi, o radical -kud ocorre seja em 'pessoa mais velha [do grupo de parentesco]', seja em 'ancestral', seja em 'tempos antigos'. Em Sango, -kota é utilizado para 'parente mais velho', para 'pessoa mais velha', para 'ancestral' ou para 'dignatário'. Em Mangbetu, -koko está presente em 'ancestral' e em 'crescer'. Entre os Mandingos, o radical ke define um feixe semântico que inclui 'idade', 'autoridade', 'senioridade' e 'ancestralidade'11. Em Kanuri, -kur está presente em termos relacionados com 'velhos tempos' e 'autoridade'12.
Podemos falar, pois, de uma associação semântica, presente em diferentes culturas africanas, entre a dimensão do crescimento, da idade, da maturidade, da antiguidade, da senioridade, da ancestralidade e da autoridade. Esse feixe condiciona a derivação semântica dos termos ao longo de uma dimensão 'adulto - pessoa mais velha [do grupo de parentesco] - ancestral'. Consequentemente, encontramos dentro desse feixe semântico a categoria geral melhor expressa pelo francês 'anciens/les grands' e aquela à qual devemos nos referir em inglês pelo termo 'ancestorlelder'. Contudo, a ulterior distinção dentro dessa categoria entre os vivos ('pessoas mais velhas [do grupo de parentesco]') e os mortos ('ancestrais') não é feita sempre nas línguas africanas. Eu defendo que a insistência na primazia conceitual dessa divisão entre os vivos e os mortos é uma distorção etnocêntrica da visão de mundo africana, uma distorção que impede nossa compreensão daquilo que nós insistimos em chamar de 'culto aos ancestrais' e de 'adoração aos ancestrais'.

A convicção etnocêntrica ocidental segundo a qual 'ancestrais' devem ser separados das 'pessoas mais velhas [do grupo de parentesco]' que estão vivas condiciona o conjunto cognitivo por meio do qual abordamos os dados africanos e teorizamos sobre eles. Nosso termo 'ancestral' significando um ascendente que está morto - é etnocêntrico não apenas denotativamente, mas também conotativamente. A tradição cultural ocidental (que inclui fantasmas) aceita que os mortos possam ser dotados de poderes extraordinários. Os mortos pertencem àquilo que nós chamamos de 'mundo sobrenatural'. Um antropólogo ocidental que trabalha em alguma sociedade africana tem facilidade em aceitar, sem maiores questionamentos, que lá as pessoas crêem que os mortos, inclusive os 'ancestrais', são capazes de feitos extraordinários, que eles podem atribuir benfazejos 'misticamente', que eles 
podem punir os vivos com doenças, que eles podem ter poderes 'sobrenaturais'. Essas crenças sobre os mortos são culturalmente aceitáveis para nós e parece-nos apropriado que esses mortos tenham um 'culto'. Contudo, de acordo com nossas concepçóes culturais, os vivos não detêm esses poderes 'místicos' simplesmente pelo fato de serem mais velhos. Se os africanos dizem que os mais velhos têm esse poder, ele deve 'derivar' de algum outro lugar; e os ancestrais, já que estão mortos, são percebidos como uma fonte apropriada desses poderes ${ }^{13}$.

Até aqui nossa interpretação teve duas ênfases opostas. Ao lidar descritivamente com crenças africanas nas etnografias, tem sido geralmente sustentado que os africanos concebem o poder das pessoas mais velhas [do grupo de parentesco] como derivado do poder dos ancestrais. Por outro lado, no nível teórico (no qual nossos pressupostos culturais vêm à tona e no qual ancestrais não podem 'existir' exceto como um símbolo e como uma abstração), a direcionalidade da explicação é exatamente revertida; os poderes dos quais os ancestrais são dotados se tornam uma 'projeçâo' dos poderes palpáveis das pessoas mais velhas [do grupo de parentesco] que estão vivas. Essa última interpretação é a essência da formulação de Fortes (1965). Mas como tratar, então, dos poderes místicos que as pessoas mais velhas [do grupo de parentesco] possuem diretamente e por conta própria, como entre os Suku? Deveriam esses poderes, por sua vez, ser vistos como re-projeçóes dos ancestrais? Quando vemos o poder que tanto os ancestrais quanto as pessoas mais velhas [do grupo de parentesco] que estáo vivas têm sobre as pessoas mais novas [do grupo de parentesco] como sendo decorrentes da senioridade per se, ambas as interpretaçóes acima acerca das 'fontes' do poder parecem descabidas. Os problemas que essas interpretaçóes tentam resolver surgem primeiramente de uma categorização etnocêntrica dos dados etnográficos.

A reformulação do problema em torno da categoria mais ampla de 'senioridade' trouxe consigo outras implicaçóes semânticas para a terminologia antropológica (e consequentemente para a teoria construída sobre essa terminologia). Falamos em 'culto' aos ancestrais e até mesmo em 'adoração' aos ancestrais. Nos seus significados modernos ${ }^{14}$, essas duas palavras em português são culturalmente apropriadas para descrever condutas relacionadas aos mortos e ao sobrenatural. Por outro lado, hesitaríamos em aplicar os termos 'culto' e 'adoração' às relaçóes que são estabelecidas com os vivos. Ainda sim, se os Suku e outros 'adorassem' suas pessoas mais velhas [do grupo de parentesco] que estão mortas, eles também 'adorariam' suas pessoas mais velhas [do grupo de parentesco] que estão vivas. Se eles têm um 'culto' às pessoas mais velhas [do grupo de parentesco] que estão mortas, esse mesmo culto se aplica às relaçóes que são estabelecidas com os vivos. Notavelmente, se as pessoas mais velhas [do grupo de parentesco] que estão vivas não são adoradas, mas apenas 'respeitadas', então também os ancestrais são apenas respeitados e nada além disso. Esses pontos são muito bem ilustrados por Kenyatta (1938, p. 265-268), quando ele discute os 'ancestrais' partindo de um ponto de vista interno da cultura Kikuyu. "Nesse relato eu náo usarei o termo [adoração] porque, por experiência prática, eu não acredito que os Gikuru adorem seus ancestrais... Eu usarei, portanto, o termo 'comunicação com os ancestrais"”. A analogia europeia de Kenyatta é reveladora: "Aparentemente há uma comunhão desse tipo com os ancestrais quando uma família europeia, em ocasióes especiais, mantém uma cadeira vazia na mesa durante a refeição - o lugar de um membro morto. Esse hábito pode ser aproximado ao comportamento dos Gikuyu a esse respeito". "As palavras 'prece' e 'adoração', gothaithaiya, goikia-mokoigoro, 
nunca são usadas ao lidar com os espíritos dos ancestrais. Essas palavras são reservadas para rituais solenes e sacrifícios voltados para o poder do invisível”. O mesmo pode ser dito acerca da pergunta relacionada àquilo que tão frequentemente é chamado de 'sacrifício':

Os dons que uma pessoa mais velha [do grupo de parentesco] dá para os espíritos dos ancestrais, assim como o sacrifício de uma ovelha feito para eles, são gestos que podem parecer preces voltadas para os ancestrais aos olhos de um outsider; mas eles não são nada além de tributos, simbolizando os dons que as pessoas mais velhas [do grupo de parentesco] que partiram teriam recebido, caso estivessem vivos, e que as pessoas mais velhas [do grupo de parentesco] recebem agora.

Ao usar termos como 'culto', 'adoração' e 'sacrifício', introduzimos paradoxos semânticos que, posteriormente, nos sentimos compelidos a explicar. Com efeito, no seminário de Salisbury do Instituto Internacional da África, foi dito que "discutiu-se abundantemente a concepção segundo a qual os ancestrais são geralmente representados como tendo um caráter punitivo" (Fortes \& Dieterlen, 1965, p. 18). Essa necessidade em entender por que um objeto de 'adoração' deveria ser 'punitivo' deriva da semântica do termo que é usado. De acordo com o relatório do seminário:

O Professor Mitchell concluiu que ancestrais parecem ser normalmente ambivalentes, conferindo puniçôes para demonstrar a autoridade legítima e exercendo benevolência quando apela-se a eles. Ele articula isso a algumas observaçóes do Dr. Turner, que citou exemplos nos quais a adoração aos ancestrais é significativa em rituais coletivos seja de solidariedade, seja de expiação, destinados a restaurar relaçóes amistosas dentro de uma comunidade. Esses rituais, conforme sugeriu o Professor Mitchell, estariam direcionados para os ancestrais em seus aspectos benevolentes, enquanto no caso dos infortúnios, o aspecto punitivo seria invocado para fornecer uma interpretação.

Essa complicação teórica é desnecessária. A atitude com relação às pessoas mais velhas [do grupo de parentesco] (mortas ou vivas) é normalmente ambivalente; ambas punem e exercem benevolência, e elas necessariamente participam na restauração das relaçóes amistosas dentro da linhagem. A complexa interpretação teórica de Mitchell ignora aquilo que quase toda etnografia e que toda afirmação descritiva geral sobre 'cultos' aos ancestrais africanos sempre enfatizaram: que as linhagens africanas são comunidades que incluem tanto os vivos quanto os mortos. Gluckman e Fortes enfatizam corretamente que os 'cultos aos ancestrais' não são a mesma coisa que os cultos aos mortos. Contudo, essa irrelevância acerca da 'mortalidade $^{15}$ dos ancestrais tem implicaçóes para o próprio idioma no qual os problemas teóricos são moldados.

Ao reconhecermos que os ancestrais africanos são acima de tudo pessoas mais velhas [do grupo de parentesco] - e que elas devem ser entendidas nos termos das mesmas categorias que as pessoas mais velhas [do grupo de parentesco] que estão vivas - podemos parar de perseguir uma multidão de problemas que nós mesmos criamos. Não há nada de surpreendente no fato de que a postura com relação às pessoas mais velhas [do grupo de parentesco] que exercem autoridade deva ser ambivalente. Fortes (1965, p. 133) aponta para o importante fato de que aquilo que importa com relação aos ancestrais é seu status jural e que (no que 
tange aos Talensi) "a personalidade e o caráter, as virtudes de uma pessoa durante seu tempo de vida não fazem diferença na obtenção de sua ancestralidade; também não fazem diferença os vícios, os sucessos, as falências, a popularidade ou a impopularidade". Todavia, nós devemos acrescentar que tampouco essas variaçóes fazem alguma diferença na autoridade inerente a senioridade; aquilo que importa nas relaçóes formais é o status formal, tanto no que tange às pessoas mais velhas [do grupo de parentesco] que estão mortas quanto àquelas que estão vivas. "Não se trata do homem por completo, mas apenas de seu status jural enquanto pai (ou personagem parental, nos sistemas matrilineares), revestido de autoridade e responsabilidade; esse sim é transmutado em ancestralidade" (Ib., Idem) Porém, de acordo com o ponto de vista proposto aqui, o que ocorre não é uma 'transmutação', mas sim uma retenção do status pela pessoa mais velha [do grupo de parentesco] que agora está morta. Ou seja, o status permanece inalterado pela morte, enquanto a relação puramente pessoal e idiossincrática com relação à pessoa mais velha [do grupo de parentesco] é necessariamente modificada. Semelhantemente, quando Fortes afirma: "A adoração aos ancestrais é uma representação ou uma extensão do componente de autoridade nas relações jurais das sucessivas geraçôes”, podemos reafirmar isso de maneira mais simples - e, diria eu, mais realista e mais condizente com as concepçóes africanas - da seguinte forma: "Depois que morrem, as pessoas mais velhas [do grupo de parentesco] mantêm seu papel nas relações jurais das geraçóes sucessivas". Na teoria de Fortes, acredita-se que as pessoas 'adquirem', depois de mortas, o poder de intervir sobre a vida de suas pessoas mais novas [do grupo de parentesco]. Eu diria que eles 'continuam' a ter seu poder.

Essa reformulação simplifica a interpretação dos dados etnográficos. De fato, na formulação de Fortes, o filho começa a 'ocupar um ofício' no 'culto' após a morte de seu pai porque ele agora se torna um adulto jural (Id., ibidem, p. 130-132). Essa sucessão significa 'expulsar um antecessor', e pode ser que realizar 'sacrifícios' aos ancestrais seja um tipo de ritual de reparação capaz de reassegurar psicologicamente; o culto aos ancestrais se torna um 'refúgio' psicológico (Id., Ibidem, p. 140-141; Idem, 1945, p. 149). Uma vez que não é possível demonstrar que esses sentimentos de culpa e seu alívio existem em todas essas sociedades, seria possível sugerir outra formulação que pareceria mais apropriada para lidar com o fenômeno geral do 'sacrifício' nos 'cultos africanos aos ancestrais', sem questionar a dinâmica psicológica específica dos Talensi. O que vemos entre eles é um contínuo de senioridade intergeracional. $\mathrm{O}$ poder do grupo de parentesco é representado para mim (um Tale), pelo meu pai, assim como seu pai representa esse poder para ele. Meu pai 'adora' (respeita) e realiza 'sacrifícios' (paga tributos) para seu pai morto, assim como eu respeito e pago tributos para ele. Quando meu pai morre, meu relacionamento com ele continua (Idem, 1959, p. 48). A cadeia de relacionamentos permanece inalterada ao longo das geraçóes, embora o método de interação com meu pai se torne necessariamente diferente quando ele está morto. Se nós expressamos essa diferença utilizando os termos 'adoração' e 'sacrifício', em contraste com os termos 'respeito' e 'dom ou tributo', é porque nós, enquanto ocidentais, consideramos que esses termos sejam mais apropriados para expressar formas de lidar com os mortos. Além disso, 'sacrifício', 'expiação' e 'culpa' correspondem a um conjunto semântico confortável para nós. Todavia, há certamente aqui, o risco de transmutar o viés semântico da cultura do observador nos problemas da etnologia do observado.

Ao tratar a expressão 'cultos aos ancestrais' 
ANCESTRAIS ENQUANTO PESSOAS MAIS VELHAS DO GRUPO DE PARENTESCO NA África $\mid 245$

como uma maneira um tanto enganadora de referir-se a um aspecto geral do relacionamento com as pessoas mais velhas [do grupo de parentesco], é possível reexaminar, sob nova luz, uma questáo que Fortes via como um quebra-cabeça. Tal quebra-cabeça está no fato de que, embora os Tiv, os Nuer e os Talensi possuam sistemas sociais baseados genealogicamente, os Tiv e os Nuer não 'adoram os ancestrais', enquanto os Talensi o fazem (Idem, 1965, p. 140). Há efetivamente um quebra-cabeça se alguém insistir em ver o culto aos ancestrais como uma projeção simbólica do sistema social. Por outro lado, do ponto de vista apresentado aqui, o culto ao ancestral é uma parte integral do sistema de relacionamentos com as pessoas mais velhas [do grupo de parentesco]. O relacionamento com as pessoas mais velhas [do grupo de parentesco] que estão mortas (ou seja, com os 'ancestrais') é visto como estando no mesmo plano simbólico que o relacionamento com as pessoas mais velhas [do grupo de parentesco] que estão vivas - e não como secundário a ele ou derivado dele. Desse ponto de vista, as semelhanças estruturais gerais entre os Talensi, os Tiv e os Nuer provavelmente não resultarão em cultos aos ancestrais similares. Aparentemente outros fatores seriam mais relevantes para o relacionamento com os ancestrais qua pessoas mais velhas [do grupo de parentesco] que estáo mortas: o significado e a estrutura da senioridade, a natureza da autoridade atribuída a ela e as crenças acerca do efeito da morte sobre o papel da pessoa mais velha [do grupo de parentesco].

Para os Tiv, a questão a ser levantada é: o que existe no relacionamento dos Tiv com as pessoas mais velhas [do grupo de parentesco] que faz com que haja uma relativa indiferença com relação às pessoas mais velhas [do grupo de parentesco] que estâo mortas? O igualitarismo difuso dos Tiv retira a ênfase da autoridade da senioridade e acaba aumentando os problemas com a autoridade - que são inerentes a esses sistemas segmentários (Bohannan, 1953, p. 31). Nem a posição genealógica nem a idade conferem, por si só, poderes especiais aos vivos, e acredita-se que os mortos não tenham efeito algum sobre os vivos (Id., Ibidem, p. 83). Em suma, as pessoas mais velhas [do grupo de parentesco] Tiv qua pessoas mais velhas [do grupo de parentesco] têm pouca influência sobre a vida de suas pessoas mais novas [do grupo de parentesco], estando as pessoas mais velhas [do grupo de parentesco] vivas ou mortas. Sua autoridade formal aqui é mínima e rasa genealogicamente. Todavia, algum tipo de relacionamento com os mortos não está de todo ausente (Bohannan, 1969, p. i; 35; 43), sendo restrita ao relacionamento com os próprios pais. Assim como para os Nuer, aqui também as pessoas mais velhas [do grupo de parentesco] não são imbuídas de autoridade e poder simplesmente em virtude de sua senioridade (Evans-Pritchard, 1940, p. 179180). A passagem das pessoas mais velhas [do grupo de parentesco] para o outro mundo não muda sua situação a esse respeito.

Embora os cultos aos ancestrais não devam ser equacionados com os cultos dos mortos, crenças sobre a morte são, contudo, relevantes, como é ilustrado pelos Songye que (por razóes bastante diferentes) também podem ser descritos como desprovidos de 'culto aos ancestrais'. Aqui, as pessoas mais velhas [do grupo de parentesco] que estão vivas têm autoridade; quando elas morrem, porém, o relacionamento com elas equanto pessoas mais velhas [do grupo de parentesco] que estão mortas não permanece, pois elas reencarnam em seus netos ${ }^{16}$.

Para concluir ${ }^{17}$, a escolha dos antropólogos pelas expressóes 'culto aos ancestrais' e 'adoração aos ancestrais' para lidar com as culturas africanas é semanticamente inapropriada, analiticamente enganadora e teoricamente improdutiva. 
Fortes enfatizou corretamente que os aspectos essenciais dessas atividades devem ser encontrados não tanto no fato de que as pessoas em questão estão mortas, mas sim na estrutura matriz na qual elas são colocadas. Contudo ele não vai longe o bastante. Ao manter o termo 'ancestral' (ao invés de usar, por exemplo, 'pessoas mais velhas [do grupo de parentesco] que estão mortas') nas suas interpretações ele continua dando peso indevivo ao fato de que as pessoas estáo mortas. O termo 'ancestral' estabelece uma dicotomia onde há um contínuo. Ao separar conceitualmente os ancestrais das pessoas mais velhas [do grupo de parentesco], nós introduzimos inconscientemente conotaçóes ocidentais aos fenômenos assim rotulados e passamos a ter que lidar com paradoxos criados por nós mesmos e com soluçôes complexas para eles. É notável que os 'ancestrais' africanos são mais mundanos e menos místicos do que (aos olhos ocidentais) deveriam ser os mortos que são objetos de adoração. Por outro lado, na África, as pessoas mais velhas [do grupo de parentesco], nos parecem mais místicas do que estaríamos dispostos a admitir que os vivos fossem. De modo semelhante, os africanos tratam suas pessoas mais velhas [do grupo de parentesco] que estão vivas com maior 'adoração' do que transmite o termo em português 'respeito', e eles tratam os ancestrais com menos 'respeito' e com mais contenção do que o termo 'adoração' permitiria.

Todos esses são paradoxos que surgem da dificuldade do nosso vocabulário para acomodar-se ao fato de que, na África, as pessoas mais velhas [do grupo de parentesco] que estão vivas e os ancestrais mortos são mais semelhantes uns aos outros do que os vivos e os mortos ocidentais podem ser; são paradoxos que surgem da dificuldade para acomodar-se ao fato de que o papel social de uma pessoa mais velha [do grupo de parentesco] não muda radicalmente quando ela cruza a linha que separa vivos dos mortos, e de que a 'ancestralidade' africana não é mais do que um aspecto do fenômeno mais amplo da 'senioridade'. O problema teórico inicial aqui não é tanto o de descobrir processos simbólicos e psicológicos profundos, mas sim o de demonstrar categorias culturais africanas e de encontrar traduçóes adequadas dessas categorias na língua ocidental que é usada para teorizar. A revisão terminológica que é proposta aqui (e a consequente revisão das categorias cognitivas dos teóricos) sugere que nossa compreensão das variaçôes naquilo que um dia chamamos de 'culto aos ancestrais' deva começar com a análise da senioridade em sociedades africanas particulares. Finalmente, essas redefinições também resolvem o quebra-cabeça de se achar que por um lado, o 'culto aos ancestrais' seja extremamente característico da África enquanto uma área cultural e que, por outro lado, ele esteja inexplicavelmente e desordenadamente ausente aqui e ali dentro dessa área. Nenhum problema desse tipo surge quando nós percebemos que o traço cultural a ser examinado não é 'ancestralidade' mas sim o fato mais amplamente presente segundo o qual os africanos respeitam a 'senioridade'.

\section{Notas}

1. N. da Trad.: Optamos por traduzir o termo em inglês 'elder' pela expressão em português 'pessoa mais velha [do grupo de parentesco]', retomando a forma como o termo aparece pela primeira vez no corpo do texto, a saber "elders of the kin-group". Efetivamente, a tradução literal do termo é a locução 'mais velho/a' entendida como uma locução substantiva ('pessoa mais velha') e não como uma locução adjetiva ('mais velho/a', cujo equivalente em inglês seria 'older'). Além disso o foco de análise do autor são as relaçóes entre as pessoas mais velhas e mais novas dentro do grupo de descendência em si mesmo - como ele torna explícito na nota 17.

Teria sido possível optar por formas alternativas de traduzir 'elder' para o português, utilizando os termos 'ancião' ou 'sênior'. Contudo, optamos por não traduzir 
'elder' por 'ancião', pois 'elder' é um termo relacional, à diferença do termo 'ancião'. Só é possível falar em 'elder' em relação a outrem dentro de um grupo (ou seja, em relação a um júnior). A posição de poder e autoridade que o 'elder' ocupa é comparativa e situacional; ela não é absoluta nem anterior à relação. Ser sênior não é ser velho em estado absoluto, mas sim ser mais velho que alguém. Por outro lado, o termo 'ancião' geralmente se aplica àquele que detém poder e autoridade em todos os momentos e em relação a todos.

Por fim, optamos por não traduzir 'elder' por 'sênior', pois Kopytoff utiliza, no presente texto, seja o termo em inglês 'elder', seja o termo em inglês 'sênior'. Assim optamos por traduzir apenas o termo inglês 'sênior' pelo seu equivalente direto em português ('sênior') e manter a diferença estabelecida em inglês entre os dois termos (i.e. 'elder' e 'sênior'). Efetivamente, o autor parece utilizar 'elder' em um sentido individual (enquanto pessoa mais velha [do grupo de parentesco]) e 'sênior' em um sentido coletivo (enquanto 'geração mais velha [do grupo de parentesco]')

2. N. do A.: A primeira versão deste texto foi entregue à $67^{\text {a }}$ Reunião Anual da Associação Americana de Antropologia, 21-4 Novembro 1968, em Seattle, Washington, sob o título: "African 'Ancestor Cults' without Ancestors?" ["Cultos Africanos aos Ancestrais' sem Ancestrais?”].

3. N. da Trad.: Optou-se por reportar as Referências Bibliográficas reportadas na obra original, pois na maioria dos casos náo existe tradução das obras em português. Na medida do possível, as Referências Bibliográficas foram adaptadas ao modelo da Revista Cadernos de Campo, ainda que faltassem algumas informações exigidas pela Revista nas Referências Bibliográficas originais. Apenas as obras de Evans-Pritchard (1940) e de Sapir (1949) foram traduzidas para o português e as referências da tradução constam nas Referências Bibliográficas.

4. N. da Trad.: O domínio político-jural do parentesco pode ser resumido como o conjunto de papéis ou cargos públicos que são ordenados de acordo com as relações de parentesco; tal domínio corresponderia, assim, ao aspecto político e religioso do parentesco. Ver Radcliffe-Brown, 1978 e Carsten, 2000.

5. N. da Trad.: Kopytoff não insere a data ao mencionar Fortes e repete o procedimento também ao mencionar o trabalho de outros autores. Nesses casos não foi possível adaptar as citaçóes ao modelo exigido pela Revista Cadernos de Campo.
6. N. da Trad.: Kopytoff utiliza o único termo em inglês 'júnior' em oposiçâo a dois termos diferentes em inglês (i.e. 'elder' e 'sênior'): por vezes ele fala de 'júnior' em relação a 'elder'; outras vezes em 'júnior' em relação a 'sênior'. Assim, no primeiro caso, optamos por traduzir o termo em inglês 'júnior' como 'pessoa mais nova [do grupo de parentesco]'; no segundo caso, optamos por traduzir os termos em inglês 'júnior' e 'sênior' pelos seus equivalentes diretos em português (i.e. 'júnior' e 'sênior').

7. N. da Trad.: Optamos por reportar a versão original dessa passagem, que consideramos um pouco confusa: "An elder's curse, always implicitly made in the name of the lineage, can only be removed by an older elder - one to whom the previous elder is a júnior".

8. N. do A.: Monica Wilson fala dos Nyakyusa cujos "parentes seniores, vivos e mortos" teriam um "poder místico sobre seus juniores" e fala também do "culto aos parentes seniores", que ela por vezes iguala ao "culto aos ancestrais" (Wilson, 1957, p. 3, 4, 226). Mas isso é exceção nos dados etnográficos. O padrão esmagador nas etnografias trata separadamente 'ancestrais' e 'pessoas mais velhas [do grupo de parentesco]', fato que pode influenciar também os dados linguísticos. No meu apanhado da literatura etnográfica acerca dos termos 'ancestrais' e 'pessoas mais velhas [do grupo de parentesco]', uma descoberta inesperada foi o quão frequentemente as etnografias discutem 'cultos aos ancestrais' e a posição das pessoas mais velhas [do grupo de parentesco] sem elucidar os termos nativos que são usados para um ou para o outro, tampouco para ambos ao mesmo tempo. Somos tentados a ver isso como reflexo da força que esses termos têm para nós enquanto termos que designam necessariamente categorias separadas. Todos nós sabemos, antes mesmo de ir a campo, que africanos têm pessoas mais velhas [do grupo de parentesco] (isto é, têm 'estrutura social') e que têm ancestrais (isto é, têm 'religião'). Quando lancei mão de uma combinação de dicionários foi um pouco mais gratificante, pois eles são limitados pelas semânticas existentes. Claro, os dicionários são ainda mais reveladores quando se pode ter, para uma única palavra africana, a gama completa dos termos correspondentes em português.

9. N. da Trad.: Nesse caso, assim como em outros nos quais o autor se remete ao uso de uma palavra em inglês comparando-a explicitamente com seu uso em outra língua, optamos por deixar o termo em inglês e por evidenciá-lo em itálico. Em outros casos, quando Kopytoff se remete ao inglês enquanto língua an- 
tropológica (podendo a mesma menção ser feita ao português, já que também ele é uma língua antropológica), optamos por traduzir os termos originalmente em inglês e substituir a locução 'word(s)/term(s)/ expression(s) in English' pela locução 'palavra(s)/ termo(s)/expressão(óes) em português'.

10. N. do A.: Curiosamente, a expressão em inlgês 'old' apresenta etmologicamente, um paralelo com a semântica do Bantu 'kulu': inglês antigo 'oud'; frísio 'alt'; nórdico antigo 'ala' ('educar', 'crescer'); e latim 'alere' ('começar', 'crescer') e 'adultu's. Com 'kulu', claro, nós estamos lidando com um termo cujo núcleo semântico presente é 'crescer', etc. e que repetidamente opera uma derivação semântica em muitas línguas (mas não em todas) em direção a 'pessoas mais velhas [do grupo de parentesco]' e, em algumas dessas línguas, em direção a 'ancestral'. Portanto, fazendo uma analogia à 'derivação linguística' de Edward Sapir, o termo 'derivação semântica' parece adequado para indicar as mudanças gramaticais paralelas que ocorrem em línguas do mesmo conjunto depois que elas se separam (Sapir, 1949, p.171.).

11. N. do A.: Comunicação pessoal do Dr. Peter M. Weill.

12. N. do A.: Homburger (1941, p. 250-251) considera que o Bantu -kulu esteja relacionado a formas como o Zande 'kuru', o Mossi 'kud-re', o Mande 'koro' e o Kanuri 'kure'. Seus núcleos semânticos são idênticos ('grande/velho/crescido') e eles apresentam derivaçôes semânticas similares em direção a 'importante', 'pessoas mais velhas [do grupo de parentesco] 'e 'ancestrais'. Essas línguas são, obviamente, relacionadas - com exceçáo talvez do Kanuri.

13. N. do A.: Quando eu estava em campo eu não tive dificuldade em aceitar a ideia de que os 'ancestrais' mortos poderiam ter poderes 'sobrenaturais'. Todavia, ao insistir em colocar questôes sobre por que e de onde vêm os poderes das pessoas mais velhas [do grupo de parentesco] que estấo vivas, eu devo ter desviado a atenção dos meus informantes. Foi necessário um ato de fé metodológico (e cultural) para aceitar como um dado etnográfico definitivo o seguinte fato: uma vez que os mortos podem fazer coisas sobrenaturais, por que os vivos não poderiam fazer também?

14. N. do A.: A palavra em inglês 'worship' carregava, certamente, uma conotação menos religiosa no inglês antigo. Nesse caso, ela se referia meramente à 'dignidade', à 'honra' e ao 'mérito', significados que são apropriados para lidar apenas com um dos dois aspectos do relacionamento africano estabelecido tanto com as pessoas mais velhas [do grupo de parentesco] quanto com os ancestrais. Contudo no inglês antigo, 'worship' perdia o segundo aspecto associado à familiaridade que esse relacionamento africano carrega e que permite censura quando necessário.

15. N. da Trad.: Optamos por traduzir por 'mortalidade' a palavra em inglês 'deadness' que não tem correspondente direto no português (trata-se de uma derivação do substantivo e do adjetivo 'dead' [morto]).

16. N. do A.: Comunicaçáo pessoal com Dr. Alan P. Merriam.

17. N. do A.: Nesse texto eu discuti apenas os 'ancestrais/ pessoas mais velhas' dentro do grupo de descendência em si mesmo, e não fiz referência alguma aos 'cultos aos ancestrais que são externos ao grupo de descência' - discutido por McKnight (1967). Resumindo brevemente, o ponto de McKnight é que os 'ancestrais externos ao grupo de descendência' (ou seja, os ancestrais paternos nos sistemas matrilineares e maternos nos patrilineares) não são benevolentes como deveriam ser nos termos da teoria de extensão dos sentimentos de Radcliffe-Brown. McNight mostra que as relações com o grupo de parentesco dos 'progenitores residuais' não precisam duplicar os sentimentos do relacionamento com aquele progenitor. Assim, em uma sociedade patrilinear, uma pessoa pode ter uma relação calorosa com a própria mãe e com o irmão dela, mas, ainda sim, pode ter relaçóes tensas e até mesmo hostis com o grupo de parentesco deles e com outros parentes dentro do grupo enquanto uma entidade corporada. São essas últimas relaçôes que condicionam as relaçôes com os 'ancestrais que são externos ao grupo de descendência'. O tipo de análise de McKnight é consistente com a análise desenvolvida aqui. Eu usaria meramente o termo 'relacionamento com as pessoas mais velhas que são externas ao grupo de descendência' ao invés de 'cultos aos ancestrais que são externos ao grupo de descendêncià.

\section{Referências bibliográficas}

BOHANNAN, Laura \& BOHANNAN, Paul. The Tiv of Central Nigeria. London, 1953. . A Source Notebook on Tiv Religion (V. I: Cosmos, Soma, Psyche and Disease). New Haven, Conn, 1969. CARSTEN, Janet. Introduction: cultures of relatedness. In: (Org.). Cultures of relatedness: New approaches to the study of kinship. Cambridge University Press: Cambridge, 2000, p. 1-36. 
ANCESTRAis ENQUANTO PESSOAS MAIS VELHAS Do GRUPO DE PARENTESCO Na África $\mid 249$

CUNNISON, Ian. History on the Luapula, Rhodes-Livingstone Papers, 21, 1951.

EVANS-PRITCHARD, Eduard. The Nuer. Oxford, 1940. [Os Nuer : uma descrição do modo de subsistencia e das instituiçóes politicas de um povo nilota. São Paulo: Perspectiva, 2002].

FORTES, Meyer. The Dynamics of Clanship among the Tallensi. London, 1945.

Oedipus and Job in West African Religion. Cambridge, 1959.

. Some Reflections on Ancestor Worship, in African System of Thought. In: FORTES, Meyer \& DIETERLEN , G. (Org.). African Systems of Thought. London, 1965.

FORTES, Meyer \& DIETERLEN, G. (Org.). African Systems of Thought. London, 1965.

GLUCKMAN, Max. Mortuary Customs and the Belief in Survival after Death among the South-Eastern Bantu, Bantu Studies, xi, 1937.

HOMBURGER, Lilias. Les Langues négro-africaines et les peuples qui les parlent. Paris, 1941.

KENYATTA, Jomo. Facing Mount Kenya: The Tribal Life of the Gikuyu. London, 1938.

KOPYTOFF, Igor. Family and Lineage among the Suku of the Congo. In: GRAY, Robert F; GULLIVER, P.H. (Orgs.). The Family Estate in Africa. London, 1964.

The Suku of Southwestern Congo. In: GIBBS, James L. Jr. (Org.). Peoples of Africa. New York, 1965.

MCKNIGHT, J. D. Extra-Descent Group Ancestor Cults in African Societies. Africa, v. xxxvii, p. 1-21, 1967.

RADCLIFFE-BROWN, A. R. Sistemas políticos africanos de parentesco e casamento. In: MELLATTI, J. C. (Org.) Radcliffe-Brown. São Paulo: Atica, [1950] 1978, p. 178-230.
SAPIR, Edward. Language. New York, [1921] 1949. [SAPIR, Edward; CÂMARA Júnior, J. Mattoso. A linguagem: introduçâo ao estudo da fala. Rio de Janeiro: MEC, 1954.]

WILSON, Monica. Rituals of Kinship among the Nyakyusa. London, 1957.

Eu usei as seguintes fontes acerca dos termos para 'ancestrais' e 'pessoas mais velhas [do grupo de parentesco]' nas línguas africanas mencionadas:

DOUGLAS, Mary. The Lele of the Kasai. London, 1963 SANGREE, Walter. Age, Prayer, and Politics in Tiriki, Kenya. London, 1966.

E usei os seguintes dicionários das respectivas línguas:

C.W.R. Tobias and B.H.C. Turvey 1954 (Ovambo/ Kwanyama), W. Holman Bentley 1887 (Kongo), R.P.A. Semain 1923 (Songye), G. Hulstaert 1952 (Nkundo/Lomongo), M. Guthrie 1935 (Ngala), M. Mamet 1955 (Ntomba), J. Whitehead 1899 (Bobangi), Edwin W. Smith 1907 and J. Torrend 1931 (Ila), C.M. Doke 1933 and 1963 (Lamba), G.M. Sanderson 1954 (Yao), C. Taylor 1959 (Ankole), Herbert W. Woodward 1882 (Bondei), C.S. Louw 1915 (Karanga), D. McJ. Malcolm 1966 and C.M. Doke and B.W. Vilakazi 1958 (Zulu), R.P. Alexandre 1953 (Mossi), B.F. and W.E. Welmers 1968 (Igbo), Charles A. Taber 1965 (Sango), A. Vekens 1928 (Mangbetu).

\section{traduzido de}

KOPYTOFF, Igor. Ancestors as Elders in Africa. Africa, v. 51, p. 129-142, 1971. 
250| IgOr KopytofF

tradutoras Claudia Fioretti Bongianino

Mestranda em Antropologia Social / UnB

Denise Ferreira da Costa

Mestranda em Antropologia Social / UnB

revisora Juliana Braz Dias

Professora Doutora em Antropologia Social / UnB

Recebida em 31/03/2012

Aceita para publicação em 01/10/2012 